\title{
Polarization and Challenged Regime Legitimacy in East Asia
}

\section{Yi Chen}

Southwest Jiaotong University, Chengdu, China

Keywords: Regime legitimacy, Ideological polarization, Legitimacy crisis, Political trust, Government performance

\begin{abstract}
This paper explains how ordinary citizens are becoming increasingly polarized about the legitimacy of the regime. Two major findings are concluded: (1) although overall regime legitimacy is higher in authoritarian regimes when compared to democracies, it is also more polarized; (2) it is found that greater polarization on the dimension of "process legitimacy" when compared to the dimension of "result legitimacy."
\end{abstract}

\section{Introduction}

Political polarization is seemingly worsening everywhere, including in established democracies such as the United States and the countries of Western Europe, as well as the newer democracies or non-democratic regimes around the world. Many of the societies outside of the established democracies that are facing worsening polarization are located in Asia. For example, in Malaysia, the legitimacy of the electoral process has been challenged by the Bersih protests. In Thailand, protestors questioned the legitimacy of the regime of Yingluck Shinawatra prior to the eventual breakdown of democracy in the coup of May 2014. In Taiwan and Hong, civil society protests questioned the legitimacy of the legislative and electoral processes respectively. While many explanations for worsening polarization have been put forward, including the media environment, the rise of populism, and ineffective governance, this paper focuses on the question of legitimacy as an explanation for polarization in East Asia, distinguishing between the dimensions of "process legitimacy" and "result legitimacy." Using data from the Asian Barometer Survey, we explain how ordinary citizens are becoming increasingly polarized about the very legitimacy of the regime. We produce two major findings: (1) although overall regime legitimacy is higher in authoritarian regimes when compared to democracies, it is also more polarized; (2) we find greater polarization on the dimension of "process legitimacy" when compared to the dimension of "result legitimacy." This research can serve as a starting point for more in-depth and systematic studies exploring the problem of worsening polarization in the region.

\section{Ideological Polarization and Polarized Regime Legitimacy}

In the political science literature, polarization has been traditionally measured around ideological cleavages. While ideological polarization may encompass multiple issues, political scientists studying Western societies have argued that the traditional left-right framework is useful for assimilating multiple cleavages and making cross-national comparisons (Fuchs and Klingemann, 1990; Knutsen, 1998). However, in East Asia, political competition is rarely structured around these traditional left-right cleavages. For example, in Taiwan, the main political cleavage is centered on national identity. In South Korea, the main cleavages are centered on regionalism and the progressive/conservative divide. In other countries such as the Philippines, electoral mobilization is primarily clientelist, and no clear ideological cleavages can be identified. The complexity and diversity of ideological political cleavages in East Asia therefore makes comparison of ideological cleavages in the region very difficult. Instead, to measure polarization in East Asia, we propose a measure of polarized regime legitimacy. This measure builds on work by scholars who show that polarization may be affective (for example the extent to which groups "like" or "trust" each other), 
rather than solely based on policy or ideological disagreements (Iyengar, Sood, and Lelkes, 2009). We hope that this measure can also be applied to East Asia to identify polarization between "in" and "out" groups, even when no obvious ideological cleavage can be identified.

In this paper, we also distinguish between the legitimacy of political processes and political outcomes in the minds of citizens. Polarized process legitimacy may occur due to disagreements between different groups in society on the legitimacy of political processes - for example, accusations of electoral malpractice or subversion of the democratic process. Polarized result legitimacy may occur due to the unequal distribution of political benefits across society or cognitive bias among partisans. We find both of these types of polarization in East Asia, but are results indicate that polarization on the "process" dimension may be stronger than on the "results" dimension.

\section{Contested Legitimacy and "Winning/Losing" Polarization in Asia}

This study covers twelve political systems in East and Southeast Asia surveyed by the Asian Barometer Survey (ABS). [1] Of these twelve countries, six countries were classified electoral democracies by Freedom House in 2015, while a further six countries were classified as non-democracies. Two further countries surveyed by the ABS, China and Vietnam, are excluded from our study since they do not hold national elections. To tap into people's assessments of process legitimacy, we measure trust in three types of institutions: political, administrative, and electoral. Political institutions are elected by citizens, and include the executive, national government, and those who run the government. Administrative institutions are supposedly politically neutral institutions, including civil service, military, and police. Finally, electoral institutions are measures of trust in the electoral commission, whether citizens believe that elections are free and fair, and whether all parties have free and equal access to the media. To tap into people's assessment of results legitimacy, we look at three measures. First, we consider the of political aspects of performance responsiveness, accountability, and control of corruption. The second measure taps into the economic aspect of performance, and includes three indicators - family economic situation, subjective economic satisfaction, and economic security. The third measure looks at social justice aspects of performance, specifically government performance on redistribution measured using items tapping into generational justice, redistribution, and equality. In order to measure polarization on each of the dimensions, we simply measure the average level of trust between supporters of the winning side and losing side in the most recent election (which we refer to as the "winner-loser gap").

\section{Legitimacy Crisis}

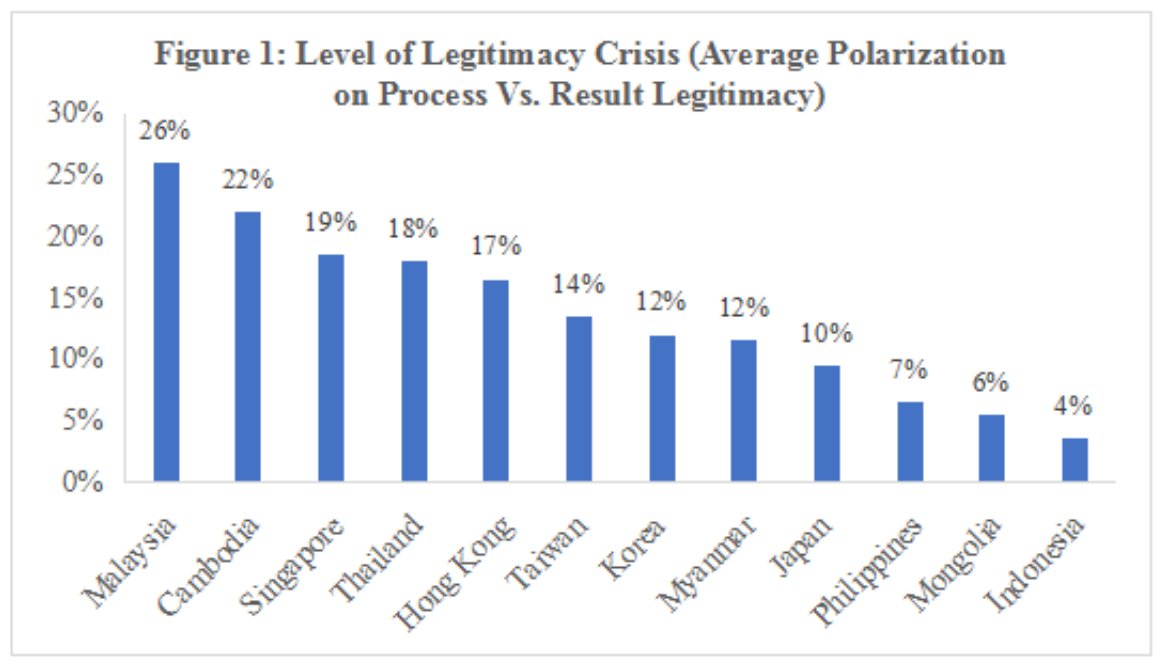

Figure 1 shows the level of polarization on the performance and result dimensions of legitimacy. Figures are the averages for polarization on the two dimensions. Polarization is consistently higher in non-democracies when compared to democracies, reflecting the fact that those who are excluded 
from power in non-democracies do not trust the regime to ensure political processes are fair or that they will benefit from the outputs of the political process. The higher levels of polarization in non-democracies can help us better understand the phenomenon of relatively high overall trust that has been observed in non-democracies (Wang, Dalton, and Shin, 2006). The five political systems with the highest levels of polarization (Malaysia, Cambodia, Singapore, Thailand, and Hong Kong) are all non-democracies. Conversely, the lowest ranking political systems, with the exception of Myanmar, are all democracies.

\section{Process or Result Legitimacy}

Second, we compare whether citizens in East Asia are more polarized on the performance or result dimensions. Figure 2, below, shows that in the twelve political systems included in this study, citizens are consistently more polarized in terms of how they view the legitimacy of the political process rather than how they view the outcomes of the political process. The highest difference between polarization on the two dimensions of legitimacy is Cambodia, at 13\%. This finding is consistent with the frequent opposition of complaints of irregularities in the political process. In Hong Kong, the figure is $11 \%$, also reflecting opposition complaints about restrictive rules for the election of the territory's Chief Executive and Legislature. In Malaysia, the difference between polarization on the performance dimension and polarization on the result dimension is $9 \%$. This finding should also not be surprising given that the Bersih protests against the government have been overwhelmingly focused on alleged irregularities in the democratic process (electoral irregularities). Other societies that have witnessed significant polarization centered on political processes, including South Korea and Taiwan, also show greater polarization on the process dimension. Both of these societies have witnesses significant opposition protests questioning the legitimacy of the political process in recent years. Even in Singapore, which has not to date witnessed significant opposition protests, opposition supporters are much more skeptical about the legitimacy of the political process than government supporters.

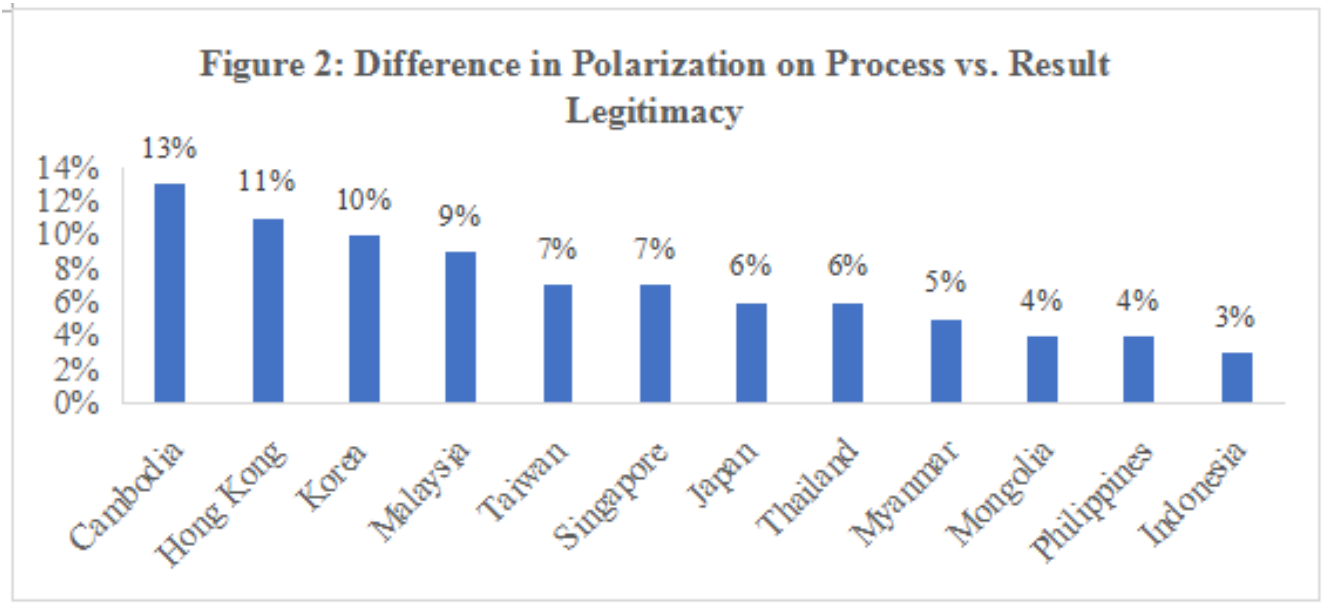

\section{Conclusions}

Scholars have often been puzzled about the relatively high levels of trust in the regime found in non-democratic political systems. Possible explanations for why citizens in non-democracies trust their regime more than their counterparts in non-democracies include regime performance in non-democracies and the phenomenon of "critical citizens" in democracies (Norris, 1999). This paper, however, shows that will citizens in non-democratic countries may be have higher levels of trust in the regime, this trust is more highly polarized than in democratic societies. In other words, the high levels of legitimacy primarily come from regime supporters. In contrast, in non-democratic regimes, trust tends to be low regardless of whether respondents supported the current government in the most recent election, producing lower levels of polarization. Second, in all of the political systems included in this study, citizens were more polarized on the process dimension of regime legitimacy when 
compared to the result legitimacy. This finding was consistent across all regime types. This suggests that governments need to be concerned about political processes as well as results in order to maintain their legitimacy among all sections of the population. Finally, in future studies, more detailed individual level analysis can help us to uncover different explanatory factors explaining regime legitimacy in different institutional contexts.

\section{References}

[1] The Asian Barometer Survey (ABS) is a comparative survey project measuring political attitudes in East Asia. Since the project was launched in 2001, a total of four survey waves have been completed. For more details about the survey, please see http://www.asianbarometer.org/

[2] Fuchs, Dieter, and Hans-Dieter Klingemann. 1990. "The Left-Right Schema." In Continuities in Political Action: A Longitudinal Study of Political Orientations in Three Western Democracies, edited by M. Kent Jennings and Jan van Deth. W. de Gruyter.

[3] Iyengar, Shanto, Gaurav Sood, and Yphtach Lelkes. 2012. "Affect, Not Ideology: A Social Identity Perspective on Polarization." Public Opinion Quarterly

[4] Knutsen, Oddbjørn. 1998. "The Strength of the Partisan Component of Left-Right Identity A Comparative Longitudinal Study of Left-Right Party Polarization in Eight West European Countries." Party Politics 4 (1):5-31.

[5] Norris, Pippa, ed. 1999. Critical Citizens: Global Support for Democratic Government. Oxford: Oxford University Press.

[6] Wang, Zhengxu, Russell J. Dalton, and Shin Doh. 2007. "Political Trust, Political Performance, and Support for Democracy." In Citizens, Democracy, and Markets around the Pacific Rim, edited by Russell J. Dalton and Doh Chull Shin. Oxford: Oxford University Press. 